\title{
DO XADREZ À INTELIGÊNCIA ARTIFICIAL: O IMPÉRIO DO DIREITO (FRANCÊS) CONTRA-ATACA
}

\section{Muriele De Conto Boscatto ${ }^{1}$}

Resumo: $O$ artigo trabalha com o recorte metodológico da inteligência artificial e a sua estruturação à resposta jurídica, ou seja, com o conceito de Direito dos algoritmos em cotejo com o interpretativismo dworkiniano. O debate Hart e Dworkin e a insistente luta deste contra o modelo descritivo de regras da teoria dos fatos sociais deu substrato à discussão e permitiu a identificação inexorável do "conjunto verdade" do robô à citada teoria positivista. O diálogo se desenvolve evidenciando a sucumbência da perspectiva técnica ao paradigma da intersubjetividade, eis que nega o lócus hermenêutico e se subsume às metafísicas clássica e moderna, para a entificação e o assujeitamento da norma jurídica, e não à resposta hermeneuticamente adequada do intérprete responsável pelo empreendimento compreensivo. O contexto francês aparece para amostrar perspectiva legislativa responsável ao trato da questão explorada. O robô é um eximo enxadrista, mas não compreende a cortesia: portanto, não pode enveredar-se à Teoria do Direito e da Decisão Judicial. A metodologia empregada é a fenomenologia hermenêutica.

Palavras-chave: Inteligência Artificial; Algoritmos; Hermenêutica; Intersubjetividade.

\section{FROM CHESS TO ARTIFICIAL INTELLIGENCE: THE (FRENCH) EMPIRE OF LAW STRIKES BACK}

\begin{abstract}
The article deals with the methodological framework of artificial intelligence and its structuring to the legal response, that is, with the law concept of algorithms in comparison with the Dworkinian interpretativism. The Hart and Dworkin debate and its insistent struggle against the descriptive rule model of social fact theory underpinned the discussion and allowed the inexorable identification of the robot's "truth set" with the aforementioned positivist theory. Dialogue develops by highlighting the succumbence of the technical perspective to the intersubjectivity paradigm, which denies the hermeneutic locus and subsumes the classical and modern metaphysics, for the understanding and subjection of the legal norm, and not the hermeneutically adequate response of the interpreter responsible for the process. comprehensive enterprise. The French context appears to sample the legislative perspective responsible for dealing with the question explored. The robot is a great chess player, but he does not understand courtesy: therefore, he cannot go into the Theory of Law and Judicial Decision. The methodology employed is hermeneutic phenomenology.
\end{abstract}

Keywords: Artificial Intelligence; Algorithms Hermeneutics; Intersubjectivity.

\footnotetext{
${ }^{1}$ Doutoranda em Direito Público pela Universidade do Vale do Rio dos Sinos. Linha de pesquisa Hermenêutica, Constituição e Concretização de Direitos. Orientadora Dra. Jânia Maria Lopes Saldanha. Advogada Empresarial e Docente da Faculdade Meridional Imed - Passo Fundo. Email muriele.boscatto@imed.edu.br.
}

Revista de Direito Urbanístico, Cidade e Alteridade | e-ISSN: 2525-989X | Belém | v. 5 | n. 2 | 


\section{INTRODUÇÃO}

A temática esboçada neste artigo se dirige à questão da inteligência artificial e a sua pretensão em alcançar o terreno da decisão judicial. Assim que o tema dialoga a proposta tecnológica com a Teoria do Direito e da Decisão Judicial e, sobretudo, com a Hermenêutica Onto-Filosófica, para verificar a condição de possibilidade da audaciosa pretensão.

O problema de pesquisa enfrentado pode ser evidenciado do seguinte questionamento: "Qual é o conceito de Direito adotado pela inteligência artificial para a desafiadora tarefa e se essa estrutura consegue responder os desacordos teóricos inerentes às proposições de verdade presentes nos casos difíceis cujos quais questões de princípios gravitam à solução jurídica e, mais, se essa resposta é hermeneuticamente adequada?".

Com hipótese de resposta, de antemão, percebe-se a insuficiência da máquina para o trato das questões de princípio, eis que, longe de uma abordagem externa, a resposta dos casos jurídicos, pressupõe imersão, na problemática concreta. Só assim é possível avaliar-se a intencionalidade dotada de valor, à resposta jurídica adequada, cotejando-a à tradição e à circularidade hermenêutica, o que ainda requer atividade interpretativa - do início ao fim para fechamento num todo coerente à melhor luz em termos de moralidade política.

Essa atividade complexa não é para quem joga xadrez, mas para quem entende uma prática cortês, e o robô, como premissa inicial, reveste-se das características de um bom enxadrista e não de um bom avaliador que lança juízos avaliativos-normativos de "dever-ser". Parece, em tese, lidar com o ser.

O objetivo geral da pesquisa esboçada nesse artigo busca cotejar o conceito interpretavista do Direito dworkiniano com a proposta descritiva do conjunto verdade da inteligência artificial, a fim de concluir a afinidade da máquina ao modelo positivista e, assim, enfrentar seriamente a sua pretensão em dar respostas jurídicas no paradigma da intersubjetividade.

A construção dos objetivos específicos parte do debate Hart e Dworkin, onde se quer revelar o contexto da Teoria do Direito, que mudou a agenda epistemológica e metodológica do Direito, para sempre se comparar com a estrutura do Direito dos algoritmos, verificandose, assim, criticamente a viabilidade da técnica para alçada que se propõe.

Se segue à apresentação do conceito interpretativista do Direito de Dworkin, mostrando a sua característica de ruptura, sobretudo, na negação do aguilhão semântico e do 
arquimedianismo, o que também vai cotejado com o comportamento do robô sobre a premissa dos desacordos constitutivos do Direito.

Por fim, se dirige a examinar o "Caso Francês", através da Lei de Programação e Reforma Judiciária, onde o Parlamento da França assumiu postura contrária à catalogação sobre perfis de juízes e estatísticas de suas decisões, especulando atitude exemplar.

Sobre as razões para o recorte metodológico da pesquisa, ousa-se afirmar seja uma das mais atuais e preocupantes discussões que a Teoria do Direito, deste conjunto histórico, terá de se afirmar. Pulverizam-se startups jurídicas com diversos escopos, assim como os Tribunais, no Brasil e no mundo, vêm reiteradamente se engajando nestas estruturas técnicas para responder à crise quantitativa e qualitativa da Jurisdição. Então que pensar sobre os limites dessa duvidosa facilitação é responsabilidade da doutrina e a sua capacidade crítica de constrangimento.

A metodologia adotada para o desenvolvimento do estudo é a fenomenologia hermenêutica.

\section{OURIÇO NÃO JOGA XADREZ E O ROBÔ JOGA?}

Em introdução ao debate que Dworkin (2010) enfrentou com o positivismo hartiano, no seu "levando os direitos a sério", o Jusfilósofo inglês cuida de mostrar como estava o direito em meados do século XIX. Para tanto, destaca os textos ingleses Salmo non Jurisprudence e Pato on Jurisprudence, mediante os quais era majoritariamente difundida a "teoria analítica do direito", que se contrapunha a "teoria do direito ética", ou seja, o estudo do que deve ser o direito, oportunidade em que também tece críticas ao realismo americano.

Macedo Júnior (2013) registra que, a partir da década de 1980, o debate teóricojurídico da contemporaneidade ganhou outra preocupação, a da natureza metodológica e epistemológica e o grande marco dessa transição, para um novo tipo de Filosofia do Direito, teve como um dos principais divisores de água os trabalhos de H. L. A. Hart.

A "virada hermenêutica" que traz relevância ao Hart tem em conta o fato de que a realidade do Direito passa depender da regra social cujo sentido depende de "nós mesmos". Hart procurou romper com a tese de fatos brutos e assume posição em relação à impossibilidade da descrição "a partir de lugar nenhum", isto é, externamente, a perspectiva humana manifestada em nossas formas de vida. (MACEDO JÚNIOR, 2013) 
Mas é Dworkin que apresenta uma teoria verdadeiramente paradigmática e de ruptura, especialmente, no seu conceito interpretativista do Direito, que leva a sério a faticidade do ser-aí-no-mundo, tendo a linguagem, então, como condição de possibilidade do desvelamento fenomenológico do ser do ente, numa relação intersubjetiva. Onde então, não se "entifica" o ser e nem se "assujeita" o ente.

A metáfora do xadrez, assim, não serve para responder o conceito adequado de Direito da intersubjetividade. Outras metáforas aparecem para melhor esclarecer o conceito de Direito paradigmático e a mais clara é a da cortesia, “do xadrez à cortesia”, de Macedo Júnior (2013). Esta, sim, verdadeiro exemplo de prática social argumentativa, que está a pressupor a intencionalidade dos participantes, dotada de significado avaliativo, desconstruindo a simplificação enganosa do fenômeno jurídico, através do “jogo de xadrez” cujo qual não envolve controvérsias sobre conceitos interpretativos.

O debate Hart e Dworkin, portanto, representa um divisor de águas na Teoria do Direito e chama relevo às temáticas sobre a objetividade da interpretação jurídica; a certeza e a verdade no Direito; o ceticismo e o relativismo moral; a separabilidade ou inseparabilidade da moral do Direito; o descritivismo e o interpretativismo do conceito de Direito.

Assim, refletir sobre o conceito adequado do Direito da contemporaneidade, aplicável à era global e tecnológica, dos robôs que se desenvolvem com a pretensão de decidir questões jurídicas, exige que se leve à sério toda essa produção teórica da insistente crítica dworkiniana ao modelo positivista, o que começa com o enfrentamento ao modelo de regras hartiano e se avança à problemática dos desacordos, fechando com o interpretativismo. Essa caminhada será, a partir de então, revisitada, dialogando com a inteligência artificial, para, na sequência, apresentar-se o exemplo francês.

\subsection{DWOKIN CONTRA O MODELO DESCRITIVO DO DIREITO}

Como esqueleto do positivismo jurídico, Dworkin elenca a natureza descritiva do Direito, separado que está de critérios de avaliação moral e afeito à tese dos fatos sociais, representado por um conjunto de padrões que determinam a sua validade em função da origem em ato de autoridade (tese de pedigree) ou no convencionalismo da regra de reconhecimento. Como decorrência, a obrigação jurídica vinculada à validade, com aposta à 
discricionariedade, para responder os casos difíceis cujos quais o modelo de regras não seja suficiente, criando a regra jurídica pós-facto. (DWORKIN, 2010)

A primeira linha da crítica de Dworkin ao modelo de regras hartiano, lançada na versão originária de "Levando os Direitos a sério", se insere na negação da diferença ontológica entre princípios e regras. Situa-se, portanto, na substancialidade da fluidez dos primeiros que, dotados de inerente carga avaliativa, na prática argumentativa, se prestam ao desvelamento fenomenológico da resposta adequada, inclusive, suficiente aos desacordos dos juristas sobre questões teóricas subjacentes, fechando o processo construtivo da interpretação jurídica, a partir de uma teoria moral da política.

Volte-se à cena: contextualizou-se a teoria do Direito pré e pós o debate que Dworkin travou com Hart. O marco da transição data o século XIX. Ora, passados quase meio século, o fisicalismo da descrição do Direito, a partir de um dado bruto ou mesmo da insistente busca da "capa de sentido" das palavras do texto como algo estático ou consentido, "ressurge das cinzas", através dos algoritmos, com a pseudo segurança das estatísticas.

$\mathrm{Na}$ onda tecnológica associada à crise quantitativa e qualitativa da jurisdição, vem eclodindo, não só no Brasil, como internacionalmente - a exemplo da França, que é aqui utilizada como paradigma -, a aposta aos robôs, dotados de inteligência artificial, compostos por um canal de entrada - banco de dados - e um de saída - por algoritmos -, criados por startups jurídicas (conhecidas por lawtechs ou legal techs), que buscam soluções para as dificuldades desse ramo do conhecimento, olvidando alcançar a Teoria do Direito e da Decisão Judicial.

A questão que fica é qual exatamente a diferença entre o Direito do xadrez e o papel dos enxadristas e o Direito dos algoritmos e o papel daqueles que o operam, sejam seus programadores ou os aplicadores em geral? Há espaço para a intersubjetividade? Há campo para os infindáveis desacordos teóricos constitutivos da prática jurídica?

São, com efeito, sobre essas questões que se precisa pensar, quando se quer tratar de respostas juridicamente adequadas compatíveis com o paradigma democrático, valendo-se da tecnologia como aliada, e não como mais um falacioso simplificador do que não se simplifica, o que parece ser o caso, vestindo-se de novo - só faltou o prefixo neo -, o que é velho e secular.

Parece que sobre isso já se acendeu a Assembleia Nacional da França, que, através do art. 33, da Lei 2019/222, de 23 de março de 2019, que regula a programação no país até 2022 
e a reforma da Justiça, declarou guerra à utilização da inteligência artificial com o objetivo de avaliar, analisar, comparar e prever a prática profissional de Juízes de seus Tribunais, assunto que será tratado no tópico seguinte como "exemplo Francês" (FRANÇA, 2019).

Antes, porém, é preciso insistir-se na luta de Dworkin contra os positivistas, a fim de alcançar-se o conceito adequado de Direito capaz de responder os problemas ou desacordos interpretativos próprios dessa área do conhecimento e da sociedade complexa em que se dialogam suas práticas e sempre cotejá-lo com a pretensão tecnológica que aqui se critica.

Volte-se à distinção que, num primeiro momento, Dworkin entendeu fundamental para a crítica ao positivismo de Hart, estabelecida na diferença entre regras e princípios, bem como o modus operandi de cada qual no conceito de Direito. Princípio é padrão que deve ser observado, não por que vá promover ou assegurar uma situação econômica, política ou social desejável, mas por que é exigência de justiça ou equidade ou alguma outra dimensão da moralidade. (DWORKIN, 2010)

Para estruturar a crítica aos positivistas quanto ao ponto, Dworkin (2010) lembra dois casos julgados pela Justiça americana, Riggs x Palmer e Henningsen x Bloomfield Motors, Inc.

O primeiro foi julgado em 1889, por um Tribunal de Novo Iorque, que teve de decidir sobre o direito à herança de um neto, beneficiário em testamento do avô, que deliberou por assassiná-lo, por motivos sucessórios. O debate do julgado partia da premissa de que "as leis que regem a feitura" concediam a propriedade ao assassino. Nada obstante, o Tribunal Nova Iorquino se constrangeu com o fato de que as leis e contratos poderiam ser limitados, na execução e efeitos, por máximas gerais e fundamentais do Direito costumeiro, referindo-se à teoria do precedente. Nesse dilema, e pautando-se na máxima de que ninguém pode lucrar da sua própria torpeza, o assassino não recebeu a herança testada. (DWORKIN, 2010)

O segundo caso foi julgado em 1969, em um Tribunal de Nova Jérsi, e discutiu até que ponto um fabricante de automóveis pode limitar a sua responsabilidade no caso do veículo apresentar defeitos. O contrato de aquisição do veículo limitava a responsabilidade da fabricante ao conserto das partes defeituosas. O adquirente, vitimado em decorrência do defeito, buscava ressarcimento de despesas médicas e outros tipos de despesas, inclusive, para os demais lesados. (DWORKIN, 2010)

Não existiam regras jurídicas ou leis específicas que afirmassem que não podia o fabricante fazer cumprir a disciplina contratual. Em que pese isso, a posição do Tribunal foi a 
favor do adquirente e a decisão teve em pauta alguns padrões de comportamento, que subjazem à ideia de que a liberdade de contratar encontra limite na igualdade entre as partes contratantes e que, assim, vige a máxima de que os Tribunais não se permitirão ser usados como instrumentos de iniquidade e injustiça. (DWORKIN, 2010)

Salienta Dworkin (2010, p. 39): “os padrões especificados nessas citações não são do tipo que tomamos como regras jurídicas. [...] Eles são diferentes por que são princípios jurídicos e não regras jurídicas". A diferença entre princípios jurídicos e regras jurídicas, assim, é de natureza lógica. Ambos referem-se a um conjunto de padrões que se aplicam em situações jurídicas específicas, mas diferem-se quanto à natureza da orientação que oferecem.

As regras são aplicadas à maneira tudo-ou-nada. Dados os fatos que a regra estipula, então, ou ela é válida, e a resposta que dela emana deve ser aceita; ou não é válida, e, nesse caso, não contribui em nada para decisão. (DWORKIN, 2010)

Os princípios não funcionam assim; não apresentam consequências jurídicas que se seguem automaticamente quando as condições são dadas. O princípio pode ou não prevalecer, mas isso não deixa de considerá-lo como princípio, que, noutro caso e noutras condições fáticas, poderá ser decisivo. Isso significa dizer também que os princípios não funcionam sob a forma do tudo-ou-nada, e, sim, possuem uma dimensão de peso ou importância e que, quando se intercruzam, aquele que vai resolver o conflito tem de levar em conta a força relativa de cada um (DWORKIN, 2010).

Daí é que, para o conceito de princípio, que tem em si essa ideia de dimensão, faz sentido perguntar que peso ele tem ou quão importante ele é, na definição do melhor sentido à decisão particular. Tal dimensão não ocorre no caso das regras jurídicas, que, na hipótese de uma regra preferir outra regra, em caso de colisão, uma afasta a outra, em virtude da sua validade à hipótese prática. Ao fim e ao cabo, uma das regras não vai ser válida, plano a que não se submetem os princípios, no fechamento (e não abertura) interpretativo que propõe.

Traçada a distinção entre regras e princípios, a questão segue à verificação da importância destas definições para aquilo que se denomina o "Direito" de uma comunidade. O papel relevante dos princípios está na solução da melhor luz para os casos difíceis, cujos quais o plano das regras já não consegue responder adequadamente, sem apostar no poder discricionário. 
Assim é que o debate em torno de os princípios, nestes moldes identificados, como critérios que vão além do plano das regras, dentre os quais, pressupostos morais são inerentes, se presta a identificar se eles criam ou não obrigação jurídica.

Dizendo de outro modo, termina por responder se, nos casos difíceis - exemplo de Riggs e Henningsen -, o juiz está tentando aplicar direitos e obrigações jurídicos presentes na intersubjetividade; ou se, abandonando um conceito interpretativista do Direito e reconhecendo-o limitado à descrição das regras sociais, o que ocorre com o positivismo, autorizado estaria extravasar o "Direito" e, com base em um ato de poder discricionário, criar novo item à legislação, para o caso particular.

Repare-se a importância dessa resposta para a problemática aqui dialogada. Qual o conceito de Direito na perspectiva da inteligência artificial programada por dados empíricos pré-definidos pela startup responsável por sua alimentação? O "xeque-mate" do algoritmo tem aptidão à dimensão de peso dos princípios e, para tal, se vale de conteúdo avaliativointencional da prática inerente? Ou resta inserto no âmbito das regras? O robô joga xadrez ou compreende adequadamente uma regra social de cortesia?

Parece inerente que a resposta sobre o conceito de Direito que trabalha com a inteligência artificial, sobretudo, para buscar sentido ao texto jurídico, segue presa no fisicalismo, e não foge ao plano das regras. O que sugere chamar-se, inclusive, o robô de positivista e, quiçá, daqueles modelos pré-hartianos, arraigados no ponto de vista externo, nem mesmo avançando à perspectiva hermenêutica cujo marco se atribui aos positivismos pós-hartianos.

Com efeito, no grau em que se encontra a tecnologia - exemplo do "Victor", que é a ferramenta de inteligência artificial de iniciativa do Supremo Tribunal Federal brasileiro em parceria com a Universidade de Brasília (UnB) cujo qual está na fase de construção de seu "conjunto verdade" (banco de dados a serem treinados por técnicas de Machine Learning, para que seja possível reconhecer padrões na base de dados do STF e fazer a indicação de peças processuais $)^{2}$ - a programação segue circunscrita à sistemas de codificação sob a lógica binária, ou seja, a partir de combinações de algoritmos pré-dispostos com capacidade, sim, de indicar, dentro dessa estrutura estática, alguma probabilidade, com grau de certeza. Mas, isso, certamente, hoje, não responde ao conceito de Direito, e já não respondia no século passado.

\footnotetext{
${ }^{2}$ Assim em matéria disponível em https://www.advogatech.com.br/blog/@ NayaraAzevedo/victor-o-primeiroprojeto-de-inteligencia-artificial-do-stf-qs3oyyu; Acesso em jul. 2019.
} 
Mesmo com o avanço das técnicas de depp learning, que capacitam a máquina à reproduzir algumas capacidades intelectuais humanas, os dados físicos e estáticos (objeto de consenso, e não dissenso) continuam inerentes à composição do locus do saber do robô. Com essa percepção, não se pode negar que a linguagem do ser-aí-no-mundo, como condição de possibilidade do desvelar do fenômeno jurídico, vai obscurecida na análise do dado fático, abafando o locus hermenêutico e priorizando o plano lógico-apofântico. Aí é que antevia Dworkin (2010, p. 119), no século passado:

O meu ponto não é que "o direito" contenha um número fixo de padrões, alguns dos quais são regras e outros, princípios. Na verdade, quero opor-me à ideia de que o 'direito' é um conjunto fixo de padrões de algum tipo.

Retomando a indagação aberta parágrafos acima, para os positivistas, claramente, se um caso não é coberto por uma regra, o juiz deve exercer seu poder discricionário, para decidi-lo mediante a criação de uma nova regra jurídica para o caso, ex post facto. A discricionariedade judicial encontra sentido diante do fato de que "os padrões jurídicos que não são regras e são citados pelos juízes não impõem obrigações a estes” (DWORKIN, 2010, p. 55).

O positivismo então adota um sentido forte ao poder discricionário ${ }^{3}$; e não consegue responder, naquilo que intitula "Direito", o por que obrigações jurídicas como a de que "ninguém pode valer-se da própria torpeza" ou de que os "Tribunais não poderão ser utilizados como instrumentos de iniquidades e injustiças", são obrigações diferentes daquelas impostas pelas regras e por que isso autoriza dizer que princípios e políticas não são parte do Direito, mas compreendem meramente padrões extrajurídicos tipicamente utilizados nos Tribunais.

Inexoravelmente, como visto, essa é a dinâmica advinda do "conjunto verdade" que integra o banco de dados dos algoritmos da inteligência artificial. A falta da previsão ou o dissenso sobre o dado empírico catalogado também não respondem os casos difíceis. Especula-se pensar que, quando a inteligência artificial alcançar toda a sua potencialidade “ápice de acurácia” -, o problema para decisão judicial vai continuar ser o como dar limite ao intérprete da norma ou que o vincula.

\footnotetext{
3 “[...] se um jurista pensa o direito como um sistema de regras e ainda assim reconhece, como deve, que os juízes mudam regras antigas e introduzem novas, ele chegará naturalmente à teoria do poder discricionário judicial no sentido forte do termo" (DWORKIN, 2010, p. 62).
} 
Para os mais otimistas, quiçá, possa o robô escolher mais certeiramente uma das várias possibilidades para resolução do caso concreto. Só que escolher - ação que denota a discricionariedade do modelo descritivo de regras positivista - não é o mesmo que decidir, como insistentemente tem mostrado Streck e a Crítica Hermenêutica do Direito ${ }^{4}$. A escolha está sempre a pressupor um juízo avaliativo subjetivo para a eleição, ocasião em que, ao invés de constitutiva, retoma-se a moral (e outros predadores, como a política e a economia) com o apelo corretivo e quem sucumbe às tentações tecnológicas é a autonomia do Direito.

É, nesse sentido, a preocupação de Streck (2011, p. 406), mesmo em texto anterior à questão da inteligência artificial e o Direito:

[...] é incorreto pensar que o intérprete - e não esqueçamos que não há possibilidade de um 'espaço não interpretativo' (um vazio de sentido) - possa deparar com 'fatos' brutos. Pensar assim é reproduzir os pressupostos da filosofia da consciência e da hermenêutica clássica (relembrando as subtilitates). Esse é o ponto fulcral: a resposta correta, isto é, a sua (inexorável) procura, acontece (Ereignen) já na précompreensão. Por isso, compreendemos (porque pré-compreendemos) para interpretar, e não o contrário. O intérprete não 'decide' para depois 'fundamentar'. Se isso fosse verdadeiro, seria possível alcançar o outro lado do abismo gnosiológico do conhecimento e depois de construirmos a ponte pela qual 'já teríamos passado'.

Dworkin (2010) volta à temática: “As regras são realmente diferentes dos princípios?”, no seu "Modelo de Regras - II", quando faz comparação entre uma literatura qualquer e as possíveis proposições que dela podem servir, explicando que o Direito é cheio dessas proposições que representam os modos como os juristas interpretam os textos de lei. Aí é que o Jusfilósofo inglês completa sobre a sua implicância ao conceito estático e descritivo do Direito fixado em padrões sejam eles quais forem, característico do modelo positivista.

Tentando resumir a tese dworkiniana sobre os "desacordos interpretativos", o que se coloca a pensar é: "como se poderia afirmar a existência de uma obrigação judicial caso sobre ela existisse uma controvérsia, inexistindo, dessa forma, uma base convencional ao seu reconhecimento?" No Direito, a controvérsia é inerente ao debate do processo.

Traduzindo essa perspectiva para a inteligência artificial, a, aqui, chamada "teoria dos algoritmos" - metaforicamente reproduzindo a crítica da "teoria da regra social" de Hart para a tentativa de mostrar o que obriga à decisão judicial -, jamais conseguirá caminhar no campo

\footnotetext{
${ }^{4}$ Essa dicotomia sobre o decidir e o escolher aparece, por exemplo, na obra "O que é isto - decido conforme a mina consciência", quando Streck lembra da roda discussão a respeito do posfácio do "Verdade e Consenso", com Marcelo Cattoni e Rafael Tomaz de Oliveira, em Seminário na Unisinos/RS, sobre "Hermenêutica e Teoria da Decisão", em 16 de outubro de 2009 (STRECK, 2012, p. 105).
} 
de responsabilidade política, ou seja, para além do nível do dado ou do texto como um mero enunciado linguístico. Se assim se queira, da "entificação do ser", considerando o privilégio conferido ao plano lógico-apofântico, em detrimento da fusão de horizontes característica da virada hermenêutica.

O que cria o dever e o que obriga, bem assim o que constitui o Direito, segue sem resposta, para casos como os Riggs e Henningsen. O robô recebe a caricatura do positivismo e resume o Direito à descrição do seu conjunto verdade. Na sua versão mais atualizada, poderá evoluir da lógica-apofântica para a escolha de uma das probabilidades, o que continua, paradigmaticamente, significar a mesma coisa.

Se, talvez, possa existir um certo fetiche pela estatística computadorizada da história, importa sanar esse preconceito do cogito de Descartes, lembrando que a faticidade vai além de um puro empirismo, bem assim o papel do intérprete é integrativo e, tal qual na literatura, além de autor, ele é responsável pela melhor arte.

É pontual a leitura de "Verdade e Consenso", de Streck (2011, p. 406), para exata compreensão da problemática que se está a enfrentar. Por amostragem, se apresenta a citação abaixo que abarca o busílis da questão:

\footnotetext{
Jamais, portanto, há respostas 'fora', como se a resposta fosse uma filtragem da 'complexidade da coisa interpretada'. Ou seja, a resposta (certa) não é um discursos adjudicador, como se fosse possível ela - a resposta - ser um conceito, e que se pudesse substituir à coisa ou 'abarcar' a 'multiplicidade' de definições/sentidos que um evento possa ter.
}

A estratégia de Dworkin ao problema dos desacordos levou em conta a analítica das razões de decidir dos juízes americanos e ingleses nos casos Elmer, MacLoughlin, Snail Darter e Brown. (DWORKIN, 2014)

Dentro da abordagem positivista, reconheceriam os seus adeptos que a ausência de decisão anterior sobre as questões de fundo nessas contendas traria a concordância de que os advogados não teriam Direito algum para descobrir. Seus debates seriam meras retóricas. Só que Dworkin (2014) chama a atenção para essa não ser a sensibilidade, na cultura política popular, que mostra preocupação mais substantiva, esperando a resposta adequada em termos de justiça e equidade. 
Qual seria a dificuldade de ser reconhecer critério de verdade nas proposições jurídicas? Não seria mais fácil para o litigante entender que realmente não haveria Direito, segundo os fundamentos que todos sabem ser os corretos? (DWORKIN, 2014)

A explicação, portanto, correta dos desacordos reside na natureza interpretativa das disputas morais e no fato em que o Direito não pode ser entendido exclusivamente com base em suas fontes sociais. O Direito tem uma fonte social e também uma fonte moral de natureza argumentativa, enraizada nas disputas morais. (DWORKIN, 2014)

Alguns críticos negam a tese dos desacordos, sob a justificativa de que tais discursos obscureceriam a função social do Direito enquanto força ideológica e evidência e, para eles, a abordagem que verdadeiramente interessaria seria a sociológica, a histórica ou científica, que ignorasse pretensão de correção no Direito.

Essa objeção fracassa em decorrência dos seus próprios critérios. Não se nega que o Direito seja um fenômeno social, mas a sua complexidade, função e consequências dependem de uma característica especial na sua estrutura. "Ao contrário de muitos outros fenômenos sociais, a prática do Direito é argumentativa" (DWORKIN, 2014, p. 17), estando, nela e por ela, a condição de possibilidade do desvelamento do sentido da norma jurídica, em respeito à intersubjetividade paradigmática.

Se traz o exemplo lançado, no ensaio "Modelo de Regras - II", sobre os papéis do sociólogo e do historiador, salientando que esses desafiam um ponto de vista externo para narrar fatos e descrever suas circunstâncias. O sociólogo, o historiador e, para o que aqui interessa, o robô, insistem em simplificar o Direito, no jogo xadrez. Diferente é a perspectiva interna dos advogados e juristas imbuídos no problema. O que eles querem não é uma análise meramente factual; querem, sim, responder qual análise jurídica é melhor fundamentada e o por que ela assim o é. (DWORKIN, 2014)

No Direito, portanto, ambas as perspectivas são importantes e cada qual deve incorporar ou levar em conta a outra. Assim como é preciso uma teoria social do Direito, são também perversas as teorias que ignoram a estrutura do argumento jurídico e a sua natureza interna cuja qual, na concepção de Dworkin, se insere no papel avaliativo do juiz, enquanto responsável político pelo empreendimento compreensivo.

Se se antecipavam questões a pensar sobre a pretensa simplificação da decisão judicial pela aposta nos robôs que aprendem, agora, se provoca refletir sobre as respostas adequadas no Direito, que precisam fugir de artifícios que ofuscam a viragem metodológica dessa área 
do conhecimento. O debate Hart e Dworkin e a luta contra os positivistas são elucidativos à conclusão negativa da inteligência artificial no Direito, estudo que se completa com a interpretação construtiva da resposta adequada equivalente ao empreendimento literário, o que se passa a expor.

\subsection{O INTERPRETATIVISMO CONTRA O ARQUIMEDIANISMO}

Para o interpretativismo dworkiniano, não interessa a descrição factual reproduzida em ato de autoridade ou aceitação. A análise dos conceitos terá o mesmo comportamento lógico na discussão literária e o impacto da lei sobre o Direito é determinado pela pergunta de qual interpretação, dentre as diferentes possibilidades admitidas pelo significado abstrato do termo, promove melhor o conjunto de princípios e políticas que oferecem a melhor justificativa política para a lei, na época em que foi votada. (DWORKIN, 2005)

Tal resposta perpassa à presença de argumentos de duas dimensões: da adequação; e da moralidade política. A dimensão da adequação é aquela que compara a teoria política para que uma justificativa se sobressaia sobre a outra. A grosso modo, registra Dworkin (2005) que alguém que sustentasse a perspectiva preferida pudesse, a partir dela, aplicar mais daquilo que está estabelecido, do que da outra. Ressalta também que, em sistemas jurídicos modernos, raramente haveria consenso sobre qual das perspectivas dialogadas fornece a melhor adequação. A dimensão da moralidade política supõe que, se duas justificativas oferecem uma adequação igualmente boa, uma delas oferece uma justificativa ainda melhor enquanto teoria política ou moral. (DWORKIN, 2005, p. 213).

No comentado capítulo 6, de "Uma questão de princípio", Dworkin afirma a sua teoria interpretativista do Direito, assentada na ideia de que a prática jurídica é um exercício de interpretação e que, para a melhor compreensão desta, deve ser comparada à interpretação literária, onde a teoria da interpretação e da crítica foram palco de profundas discussões.

Já reconhecidos os desacordos teóricos, ou seja, as proposições teóricas de verdade que podem surgir frente a um caso difícil, a questão, para Dworkin, afinado ao Direito anglosaxão, está em saber qual sentido se deve dar na descrição desses enunciados. A dificuldade, porém, surge por que as proposições de Direito parecem ser descritivas - dizem respeito a como as coisas são no Direito, e não como deveriam ser. (DWORKIN, 2005)

Revista de Direito Urbanístico, Cidade e Alteridade | e-ISSN: 2525-989X | Belém | v. 5 | n. 2 | 
Segundo Dworkin (2005, p. 221), isso só funcionaria para casos fáceis, quer dizer, que tenha havia algum evento de natureza legislativa que subsuma o fato. Caso contrário, a análise descritiva dos "trechos da história" é falha. Conclui:

[...] as proposições de Direito não são meras descrições da história jurídica, de maneira inequívoca, nem são simplesmente valorativas, em algum sentido dissociado da história jurídica. São interpretativas da história jurídica, que combina elementos tanto da descrição quanto de valoração, sendo porém diferente de ambas.

Para valer-se do empreendimento proposto por Dworkin, os juristas devem ver a interpretação literária sob certa luz. A primeira observação é a de que não se parte de interpretações de passagens isoladas, mas do significado da obra como um todo. A segunda observação reside na "hipótese estética", preocupada que está com a apresentação da maneira de ler o texto que o revela como a melhor obra de arte. (DWORKIN, 2005)

Isto quer dizer que "qualquer um que interpreta uma obra de arte vale-se de convicções de caráter teórico sobre a identidade e outras propriedades formais da arte, assim como de opiniões mais explicitamente normativas sobre o que é bom na arte" (DWORKIN, 2005, p. 225-226). A interpretação, dentro desse contexto, deixa de ser simplesmente a busca daquilo que o autor quis passar, mas passa a ser candidata para o desvelamento da melhor resposta para a questão substantiva colocada pela interpretação.

Nessa conjectura, há diferentes papéis: do artista na criação de uma obra de arte; e do crítico que a interpreta posteriormente. $\mathrm{O}$ artista não pode criar nada sem interpretar enquanto cria, ou seja, deve, pelo menos, possuir uma teoria tática de que aquilo que produz é arte e o por que é uma obra de arte melhor por esta e não por aquela técnica. O crítico cria quando interpreta, pois, embora limitado pelo fato da obra, definido nas partes formais e acadêmicas de sua teoria da arte, seu senso crítico mais prático está comprometido com a responsabilidade de decidir qual maneira de ver, ler ou compreender aquela obra a mostra como arte melhor. (DWORKIN, 2005)

Para melhor compreensão dos papeis e cotejá-los ao seu "método" de análise jurídica, Dworkin (2005) apresenta o paradigma do "romancista em cadeia". Sugere que um grupo deles seja contratado para um determinado projeto e que se jogue dados para definir-se a ordem do jogo, qual deles começa e quais seguem o projeto. 
O primeiro romancista, que escreve o capítulo de abertura do romance, tem às mãos o direcionamento das intenções da obra. Os demais têm séria responsabilidade com o que já foi escrito e assim a atenção para continuarem o mesmo romance. Por outro lado, têm a liberdade de criar perspectivas que contribuam à trama, não fugindo da proposta inicial. (DWORKIN, 2005)

Tem-se a clareza quanto à responsabilidade de "interpretar" e de "criar", construindo os romancistas um romance único, integrado, em vez de, por exemplo, uma série de contos independentes com personagens do mesmo nome. (DWORKIN, 2005)

"Decidir casos controversos no Direito é mais ou menos como esse estranho exercício literário" (DWORKIN, 2005, p. 237). Cada juiz, então, é como um romancista na corrente. Ele deve ler tudo que os outros juízes escreveram no passado, não apenas para descobrir o que disseram ou o seu estado de espírito quando o disseram, mas para chegar a sua convicção sobre o que esses juízes fizeram coletivamente.

Ao decidir o novo caso, cada juiz deve se considerar como parceiro de um complexo empreendimento em cadeia, do qual as inúmeras decisões, estruturas, convenções e práticas são a história; e é seu trabalho continuar a história. Então que o juiz deve interpretar os antecedentes históricos e determinar o seu próprio julgamento tendo em conta o propósito desta prática até então presente. (DWORKIN, 2005)

A interpretação da prática jurídica também tem em conta a dupla dimensão: (1) deve ajustar-se à prática; e (2) demonstrar a sua finalidade ou valor.

$\mathrm{O}$ afinamento à prática, estreita a perspectiva dworkiniana à filosofia da linguagem, reclama atenção à historicidade/faticidade, com limite na tradição, o que incluirá alguma concepção da integridade e coerência do Direito como instituição; e o fechamento interpretativo de cariz substantivo, ou seja, a verificação da finalidade ou valor, importa pensar o Direito como empreendimento político.

A partir da experiência literária, sabe-se que a interpretação construtiva que o Direito exige “[...] não é uma licença para que cada juiz descubra na história doutrinal seja o que for que pensa que deveria estar lá” e é, por isso, que, já na década de 1980, Dworkin (2005, p. 240) antevia sabiamente a preocupação do Direito dos algoritmos, explicando:

Não existe, é claro, nenhum algoritmo para decidir se uma determinada interpretação ajusta-se satisfatoriamente a essa história para não ser excluída. Quando uma lei, Constituição ou outro documento jurídico é parte da história doutrinal, a intenção do 
falante desempenhará um papel. Mas, a escolha de qual dos sentidos, fundamentalmente diferentes, da intenção do falante ou do legislador é o sentido adequado, não pode ser remetida à intenção de ninguém, devendo ser decidida, por quem quer que tome a decisão, como uma questão de teoria política.

A identidade do fenômeno interpretativo da literatura e do Direito, tal como proposto por Dworkin, fecha a constatação dos diferentes papéis, do artista e do intérprete, somando, também, na interpretação jurídica, mesma estrutura: a interpretação da "prática jurídica" - não exatamente como uma espécie de estatística das intenções dos juízes ou outras autoridades, mas o exame da prática como um todo, com a responsabilidade na justificativa da perspectiva mais adequada em termos políticos - com o limite na integridade e coerência; e mais a base normativa de convicção sobre o que o Direito deve-ser e para o que deveria-servir.

É importante o enfrentamento que o Jusfilósofo teve com críticos que insistiam que os significados do texto jurídico estariam "simplesmente ali", ou seja, que a interpretação não passaria da descoberta de fatos concretos, não interpretativos e recalcitrantes. A discussão mais profícua ao tema diz com a resistência na afirmação da diferença entre os atos de criar e interpretar.

Interpretar é diferente de criar e a aquela tem em conta "convicções interpretativas" de dois níveis, de forma e de substância, que funcionam como controles recíprocos. Quando separada, metodologicamente, a leitura responsável da prática jurídica do seu âmbito valorativo da moralidade política e a decisão da melhor luz nestes termos, acontece de o primeiro plano da interpretação restringir a atividade inventiva do segundo plano, como no romance em cadeia, em que o segundo romancista encontra alguns entraves à atividade inventiva, devendo manter padrões de coerência e integridade, ao invés de um novo romance.

Nada obstante, porém, não se está a falar que todos os possíveis significados e interações estariam limitados na primeira narrativa, num "simplesmente ali" mal-empregado. E aí é que vem o papel das convicções interpretativas substantivas, permitindo e incentivando essa melhor luz.

Dworkin (2005, p. 255), então, nega a objeção, afirmando que a construção da interpretação que pretendeu demonstrar parte dum "conjunto de convicções complexas e inter-relacionadas que confrontam a experiência com um todo coerente”. Portanto, para além da descrição meramente factual ou da resposta da máquina, e sim o interpretativismo que é ontologicamente diferente da criação. 
Assim é que, no interpretativismo dworkiniano, não encontra espaço para o Direito estático dos algoritmos, reiterando a importância da discussão para a Teoria do Direito, ainda no século passado, quando - e assim se mantém - a temática da vez dizia com a insuficiência do conceito descritivo de Direito, pautado nos Fatos Sociais. Essa é a bandeira do positivismo e que também dá condições de afirmar-se que, no tocante à inteligência artificial, vende-se a ideia do novo, mas com a armadilha do velho.

A inteligência artificial pressupõe a integração do conjunto verdade, de onde ("simples ali”) os cruzamentos lógicos algorítmicos produzirão suas respostas. Tal caracterização nega o dissenso que constitui o Direito e que coloca a característica interpretativa dos fatos sociais, com relevo não só das convicções de forma, mas, das convicções de substância cujas quais a moral integra o conteúdo da resposta jurídica, para, na integridade e coerência dos princípios, revelar a compreensão correta do Direito.

Vários entraves à aposta dos robôs para simplificar a atividade interpretativa do Direito são expostos. O problema é de cariz metodológico e epistemológico. O Direito precisa é de propostas teóricas de ruptura, que, aliadas ao paradigma da intersubjetividade, não se prestem à entificar ou assujeitar sentidos. Essas respostas ficam presas na metafísica clássica ou moderna. Para ser intersubjetivo, tem que reconhecer a faticidade; o horizonte de sentido que extravasa o "simplesmente ali" e que tem na linguagem do "ser-aí-no-mundo" a condição de possibilidade da compreensão do fenômeno, notadamente, jurídico.

$\mathrm{O}$ plano do dado que caracteriza a inteligência artificial sucumbe à viragem hermenêutica e o robô dos algoritmos tem na avaliação externa - do enxadrista - a resposta que só seria possível levando-se a sério a intencionalidade, que se dá na perspectiva interna dos juristas vinculados à prática e que é orientada pelo valor. Estrutura que depende da circularidade hermenêutica dessa prática jurídica como um todo, com o fechamento nos princípios, para a compreensão adequada da norma jurídica.

Sim, o robô - positivista - cai no aguilhão semântico e insiste no arquimedianismo; aplausos à iniciativa do Estado Francês, que, através da Lei da Reforma da Justiça e que regula a programação da país nos próximos anos, proibiu e criminalizou a catalogação de decisões judiciais, para formação do banco de dados da inteligência artificial, para fins de estatísticas do modo de decidir dos seus juízes. Sobre isso que se trata a seguir.

\section{O "XEQUE-MATE" DO ESTADO FRANCÊS CONTRA O ROBÔ ENXADRISTA}

Revista de Direito Urbanístico, Cidade e Alteridade | e-ISSN: 2525-989X | Belém | v. 5 | n. 2 |

p. 41 - 62 | Jul/Dez. 2019. 
Em março de 2019, a França concluiu estudo que já vinha direcionando, pelo Ministério da Justiça e as Comissões, há, no mínimo, dois anos antes, sobre impactos e discussões necessárias à jurisdição francesa, especialmente, no atinente à proteção da publicidade de dados de decisões judiciais. A definição se deu com a aprovação da Lei n. 2019-222, de 23 de março de 2019, nominada Loi de programmation 2018-2022 et de reforme pour la justice, pela Assembleia Nacional da França e promulgada pela Presidente da República. (FRANÇA, 2019)

Dentro da pauta de crise, o Legislador francês inseriu o compromisso com a iniciativa global sobre a abertura de dados ao maior acesso dos concidadãos. Porém, se propôs a fazer isso tendo em conta a coerência entre os regimes de acesso e uma responsável disseminação das decisões de suas jurisdições: judicial e administrativa.

Na primeira mão, se opôs à revelação que possa minar a segurança ou o respeito à vida privada, na divulgação em formato eletrônico, de elementos que permitam identificar as partes, os terceiros e os profissionais da Justiça, nas decisões de seus Tribunais. Nestes termos, registra o "Artigo 19", da Exposição de Motivos, no item a que chama de "refundação da justiça" e que fomenta o debate que se intensifica nos diversos Relatórios que culminam com a negação da utilização de dados de decisões judiciais para fins de estatísticas. (FRANÇA, 2019)

Pois bem que se chega a proposta legislativa contemplada e discutida na redação do art. 33, inciso IV, alínea 1, da Lei 2019-222 cujo qual prevê textualmente, em relação às decisões relativas à matéria judicial:

IV.-Le chapitreuniquedutitreIerdu livre Ierducode de l'organisationjudiciaire est ainsimodifié :

$1^{\circ}$ Lesdeux premiers alinéas de l'article L. 111-13 sontremplacés par troisalinéasainsirédigés :

«Sousréservedesdispositionsparticulièresquirégissentl'accèsauxdécisions de justice et leurpublicité, lesdécisionsrendues par lesjuridictionsjudiciairessontmises à ladispositiondupublic à titregratuitsous forme électronique.

" Lesnom et prénomsdespersonnesphysiquesmentionnéesdansladécision, lorsqu'ellessontparties ou tiers, sontoccultéspréalablement à lamise à ladispositiondu public. Lorsquesadivulgation est de nature à porteratteinte à lasécurité ou aurespect de lavieprivée de cespersonnes ou de leur entourage, est égalementocculté tout élémentpermettant d'identifierlesparties, lestiers, lesmagistrats et lesmembresdugreffe.

« Lesdonnées d'identitédesmagistrats et desmembresdugreffe ne peuventfairel'objet d'une réutilisationayantpourobjet ou poureffet d'évaluer, d'analyser, de comparer ou 
de prédireleurs pratiques professionnellesréelles ou supposées. La violation de cetteinterdiction est puniedes peines prévuesauxarticles 226-18,226-24 et 226-31 ducodepénal, sanspréjudicedes mesures et sanctionsprévues par laloi n ${ }^{\circ} 78-17$ du 6 janvier 1978 relative à l'informatique, auxfichiers et auxlibertés. » $;^{5}$

O exemplo francês que se coloca em debate neste artigo está na previsão da norma que veda a utilização dos dados das citadas decisões para fins de avaliar, analisar, comparar ou prever as práticas profissionais reais ou alegadas dos magistrados. Com isso, a França, mesmo que indiretamente, foi a precursora de uma linha de combate à propagação das "startups jurídicas”, da facilitação da compreensão judicial, a partir de dados estatísticos.

A conclusão a que chegou o Parlamento francês está em consonância com o diálogo proposto acima e passa a representar, portanto, paradigma de respeito à Teoria do Direito e da Decisão Judicial, no combate à inescrupulosa pretensão da tecnologia dos dados em alcançar o delicado terreno da atividade jurisdicional e da interpretação da norma jurídica.

Antes de finalizar, importa ainda, no paradigma que se propôs apresentar, evidenciar a queixa engendrada perante o Conselho Constitucional francês sobre a possível não recepção à Carta de Direitos do Homem e do Cidadão de 1789, nos arts. 6 e 16, da previsão lançada no citado artigo 33 da Lei aqui destacada.

Alguns Deputados discutem a proibição da reutilização dos nomes dos juízes para detectar suas práticas profissionais, afirmando que tal posição nega um melhor conhecimento da jurisprudência, o que, na suas vistas, se conciliaria com o princípio da igualdade entre os litigantes. Criticam, a vedação com supedâneo no princípio da igualdade e no direito a um julgamento justo, além da liberdade de opinião, expressão e comunicação, que perfazem um princípio que chamam de "princípio da divulgação pública”. (FRANÇA, 2019)

\footnotetext{
5“IV.- O singular capítulo do título I do livro I do código da organização judiciária é assim modificado: $1{ }^{\circ}$ Os dois primeiros parágrafos do artigo L. 111-13 são substituídos por três parágrafos do seguinte modo: "Sob reserva das disposições especiais que regem o acesso e a publicidade das decisões judiciais, as decisões judiciais são disponibilizadas gratuitamente ao público em formato eletrônico. "Os sobrenomes e nomes próprios das pessoas singulares mencionadas na decisão, quando são partes ou terceiros, são obscurecidos antes da disponibilização ao público. Quando a sua divulgação é susceptível de prejudicar a segurança ou o respeito da privacidade dessas pessoas ou sua comitiva, também está oculto qualquer elemento que permita identificar as partes, os terceiros, os magistrados e os membros do registro. "Os dados de identidade dos magistrados e membros do Registro não podem ser reutilizados com a finalidade ou efeito de avaliar, analisar, comparar ou prever suas práticas profissionais reais ou alegadas. A violação desta proibição é punida com as penalidades previstas nos artigos 226-18,226-24 e 226-31 do Código Penal, sem prejuízo das medidas e sanções previstas pela Lei ${ }^{\circ}$ 78-17, de 6 de janeiro de 1978, relativa ao tratamento de dados, arquivos e liberdades". (FRANÇA, 2019).
} 
A decisão pela constitucionalidade veio com a Decisão 2019-778, de 21 de março de 2019, do Conselho Constitucional da França, fundamentando que a previsão não cria qualquer distinção injustificada entre os indivíduos e não infringe o direito a um julgamento justo e equitativo que garanta a paridade de armas entre os litigantes na prática judicial. Há menção a possível falta consciência dos dissidentes sobre a verdadeira intenção da proposta legislativa proibitiva, preocupada que está com a baixa leitura da resposta estatística, o que, ao invés de favorecer elementos de superação da crise da jurisdição, coloca em risco o funcionamento da justiça.

Pelo fato de a França ter sido o primeiro país a enfrentar o avanço dos algoritmos à seara jurisdicional, respeitando os entraves da Teoria do Direito à simplificação difundida, vai aqui destacada a postura como modelo ao tratamento legislativo da problemática.

\section{CONCLUSÃO}

O presente artigo prendeu, assim, desafiar talvez uma das mais atuais preocupações do Direito deste tempo e, especialmente, o fez tendo por pano de fundo a principal discussão da Teoria do Direito ainda do século de XIX, mas que, reiteradamente, precisa ser chamada à cena para lembrar do contexto de ruptura paradigmática cujo qual se assenta.

Então que o Direito dos algoritmos foi colocado em xeque para discutir seu lugar com o interpretativismo dworkiniano. $\mathrm{O}$ chão em que se alicerçou o ensaio foi o debate Hart $\mathrm{x}$ Dworkin e a insistente luta deste último contra o positivismo e a sua caraterística descritiva do Fato Social ao conceito de Direito.

Nessa medida, cotejaram-se essas grandes discussões, para concluir-se que os entraves que lá estavam, na caricatura do positivismo, aos robôs se estendiam a ponto de chamar-se a máquina de positivista e pré-hartiana, na sua melhor versão, exima enxadrista, mas jamais competente à resposta jurídica adequada aos casos difíceis.

Isso porque, nesses casos, a premissa que constitui o Direito é o desacordo teórico na colisão de questões de princípio, onde é necessário não só o contexto histórico, mas critérios de verdade, como a moral, para desvelamento fenomenológico, com atenção à responsabilidade política do intérprete - reflexamente limitado à intersecção de convicções de forma e de substância - à melhor leitura possível da tradição jurídica, em termos de moralidade política, em fechamento do empreendimento compreensivo. 
O robô sucumbe à viragem hermenêutica e, portanto, limita a sua resposta no plano apofântico do sentido. No seu estado atual, de lançamento de dados empíricos à formação do conjunto verdade, o robô consegue entificar a norma jurídica. Amanhã, quando o robô estiver no ápice de acurácia, sua atividade representará a melhor escolha, algorítmica, do conjunto de probabilidades estatísticas que suporta, quando aí assujeitará a norma.

Os casos difíceis - Riggs x Palmer na década de 1960 já mostrava - continuam sem resposta. Isso porque não partem dessa premissa estática. Assim, o que obriga e o que vincula continuará fora do "modelo de regras" ou do "conjunto verdade" e, pronto, volta-se à escolha - que, no Direito, tem nome de "discricionariedade" - sendo a responsável pela resposta do problema.

Essa resposta não é nova; a agenda metodológica e epistemológica, na Teoria Jurídica, virou com o debate Hart e Dworkin. Então que, mais outra vez, a aposta da inteligência artificial para a decisão judicial nada mais é do que o velho positivismo transvertido com as características da era tecnológica.

\section{REFERÊNCIAS}

COSTES, Josiane. Ata de Reunião de 23 de outubro de 2018. Disponível em: https://www.senat.fr/seances/s201810/s20181023/s20181023_mono.html\#Niv1_SOM3.

Acesso em 30 de jul. 2019.

DWORKIN, Ronald. Levando os direitos a sério. trad. Nelson Boeira. 3 ed. São Paulo: Martins Fortes, 2010, p.

. O império do Direito. trad. Jeferson Luiz Camargo. 3 ed. São Paulo: Martins Fontes, 2014, p. 20-38.

- Uma questão de princípio. trad. Luís Carlos Borges. 2 ed. São Paulo: Martins Fontes, 2005, p. 213.

FRANÇA. Lei 2019-222, de 23 de março de 2019. Institui regras de programação de 2018 a 2022 e a reforma da justiça. Paris: Presidência da República, 2019. Disponível em: <https://www.legifrance.gouv.fr/affichTexte.do;jsessionid=C962374BA942EE87873AE3DD

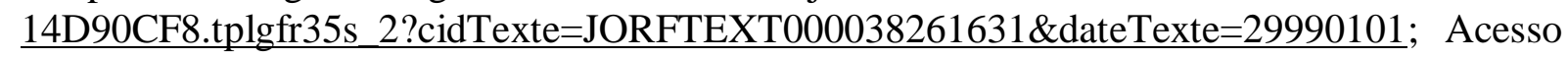
em: jul. 2019.

FRANÇA. Conselho Constitucional. Decisão n. 2019-788 DC. Lei 2019-222. Programação 2 018-2022 e de reforma da justiça. Constitucionalidade. Paris/Fr, 21 de março de 2019 
Disponível em: https://www.conseil-constitutionnel.fr/decision/2019/2019778DC.htm. Acesso 31 jul. 2019.

GUEST, Stephen. Ronald Dworkin. 2 ed. Edinburgh University, 1997.

HART, H. L. A. O conceito de direito. 3 ed. Tradução de A. Ribeiro Mendes. Lisboa: Calouste Gulbenkian,

MACEDO JÚNIOR, Ronaldo Porto. Do xadrez à cortesia: Dworkin e a teoria do direito contemporânea, p. 9.

STRECK, Lenio Luiz. Hermenêutica Jurídica e(m)Crise: uma exploração hermenêutica da construção do direito. 8 ed. Porto Alegre: Livraria do Advogado, 2009.

Jurisdição constitucional e a decisão juridical. 3 ed. São Paulo: Revista dos Tribunais, 2013. 2018.

30 anos da CF em julgamentos: uma radiografia do STF. Rio de Janeiro: Forense,

O que é isto - decido conforme a mina consciência? 3 ed. Porto Alegre: Livraria do Advogado, 2012, p. 105).

Verdade e consenso: constituição, hermenêutica e teoriasdiscursivas. 4 ed. São Paulo: Saraiva, 2011, p. 406.

TERLIER, Jean. Relatório Completo das Sessões de 18 de fevereiro de 2019. Disponível em: http://www.assemblee-nationale.fr/15/cri/2018-2019/20190155.asp\#P1624521; Acesso em 30 de jul. 2019. 